\title{
Immunoreactivity for Interleukin-33 in Allergic Airway Inflammation
}

Cristan Herbert ${ }^{1}$, Melissa M. Bunting ${ }^{1}$, Neil Lambie ${ }^{2}$, Paul S. Thomas ${ }^{1,3^{*}}$ and Rakesh K. Kumar ${ }^{1}$

${ }^{1}$ Inflammation and Infection Research, School of Medical Sciences, UNSW Australia, Sydney, 2052, Australia

${ }^{2}$ Department of Pathology, Prince of Wales Hospital, Sydney, 2031, Australia

${ }^{3}$ Department of Respiratory Medicine, Prince of Wales Hospital, Sydney, 2031, Australia

*Corresponding author: Paul S. Thomas, Inflammation and Infection Research, UNSW Australia, Sydney, 2052, Australia, Tel: +61-2-9382-4631; E-mail: Paul.Thomas@unsw.edu.au

Rec date: Oct 13, 2014, Acc date: Jan 10, 2015, Pub date: Jan 12, 2015

Copyright: ( 2015 Thomas PS, et al. This is an open-access article distributed under the terms of the Creative Commons Attribution License, which permits unrestricted use, distribution, and reproduction in any medium, provided the original author and source are credited.

\begin{abstract}
Interleukin (IL)-33 is a cytokine that has key roles in the induction and perpetuation of allergic inflammation. It is strongly expressed by airway epithelial cells, but there is controversy about whether immunoreactivity is localised only to the nucleus or is also present in the cytoplasm. We investigated IL-33 immunoreactivity in airway tissues in a mouse model of an acute exacerbation of chronic asthma, in human asthmatic airway tissue, and in airway tissue from patients with allergic bronchopulmonary aspergillosis. We demonstrated that cytoplasmic immunoreactivity in airway epithelial cells was dependent both upon the target species and the severity of the allergic inflammatory response. Furthermore, using double immunolabelling, we showed that immunoglobulin-synthesising plasma cells express high levels of IL-33, which could contribute to allergic inflammation.
\end{abstract}

Keywords: Interleukin-33; Airway inflammation; Asthma; Airway epithelium; Plasma cells

\section{Introduction}

Interleukin (IL)-33 is a member of the IL-1 family that plays important roles in the induction and perpetuation of the Th2-biased immunological response associated with allergic disease, including allergic asthma $[1,2]$. Expression of mRNA for IL-33 is increased in airway and lung tissues in mouse models of allergic inflammation of the airways $[3,4]$. However, there is controversy about the cellular and subcellular localisation of IL-33 protein, as assessed by immunohistochemistry.

IL-33 was initially described as a chromatin-associated nuclear factor, and expression of the protein as assessed by immunohistochemistry was suggested to be primarily limited to endothelial and epithelial cells [1]. In human studies of non-inflamed tissues, immunoreactivity has mainly been localised to the nuclei of cells $[1,2]$. However, in at least two studies of human asthmatics, cytoplasmic staining of airway epithelial cells (AEC) has been demonstrated $[5,6]$. This may be biologically relevant, because failure to maintain nuclear localisation of IL-33 may contribute to nonresolving chronic inflammation [7] which is a key feature of disease states such as asthma. In this context, it is noteworthy that several studies have also revealed immunoreactivity of inflammatory cells, and cytoplasmic immunostaining for macrophages has been demonstrated in mouse models of allergic airway disease [3,8,9]. Similarly, cytoplasmic staining of epithelial cells, as well as of inflammatory cells with the morphology of macrophages and plasma cells, has been demonstrated in human inflammatory bowel disease [10].

Nevertheless, some investigators have asserted that immunoreactivity for IL-33 is exclusively localised to the nuclei of epithelial cells, and have dismissed cytoplasmic staining in the setting of experimental colitis as non-specific, on the basis that it was still observed in IL-33 gene-targeted mice [11].
Therefore, we investigated the expression of IL-33 in the airways in a well-validated experimental model of an acute exacerbation of mild chronic asthma, as well as in control and asthmatic human airway tissue, and in airway tissue from severe allergic disease.

\section{Materials and Methods}

\section{Experimental model}

The protocols we employed for sensitisation and inhalational challenge have previously been described [12,13]. Briefly, female $\mathrm{BALB} / \mathrm{c}$ mice aged 7-8 weeks received intraperitoneal injections of 50 $\mu \mathrm{g}$ of alum-precipitated chicken egg ovalbumin (OVA) (Sigma Australia) 21 and 7 days before inhalational challenge. Mice were exposed to aerosolised OVA in a whole body inhalation exposure chamber (Unifab Corporation, Kalamazoo, MI). Chronic low-level challenge involved exposure to $\approx 3 \mathrm{mg} / \mathrm{m} 3$ OVA for $30 \mathrm{~min} /$ day on 3 days/week for 4 weeks. Thereafter, a single-moderate level challenge $\left(\approx 30 \mathrm{mg} / \mathrm{m}^{3}\right)$ was used to induce an acute exacerbation. Particle concentration within the chamber was continuously monitored. All procedures complied with the requirements of the university's Animal Care and Ethics Committee (reference number: 08/09B).

\section{Immunostaining for IL-33}

Immunoperoxidase staining of sections of mouse trachea was performed as previously described [14]. Expression of IL-33 was detected using an affinity-purified goat antibody to mouse IL-33 (R\&D Systems, Minneapolis, MN) or an affinity-purified rabbit antibody to human IL-33, predicted to cross-react with both mouse and rat IL-33 (Abcam, Cambridge, UK). The latter antibody was also used for immunoperoxidase staining of human airway tissues from archival samples (South Eastern Sydney and Illawarra Area Health Service reference number: HREC 09/171). 
Citation: Herbert C, Bunting MM, Lambie N, Thomas PS, Kumar RK (2015) Immunoreactivity for Interleukin-33 in Allergic Airway Inflammation. J Cytol Histol 6: 302. doi:10.4172/2157-7099.1000302

Page 2 of 4

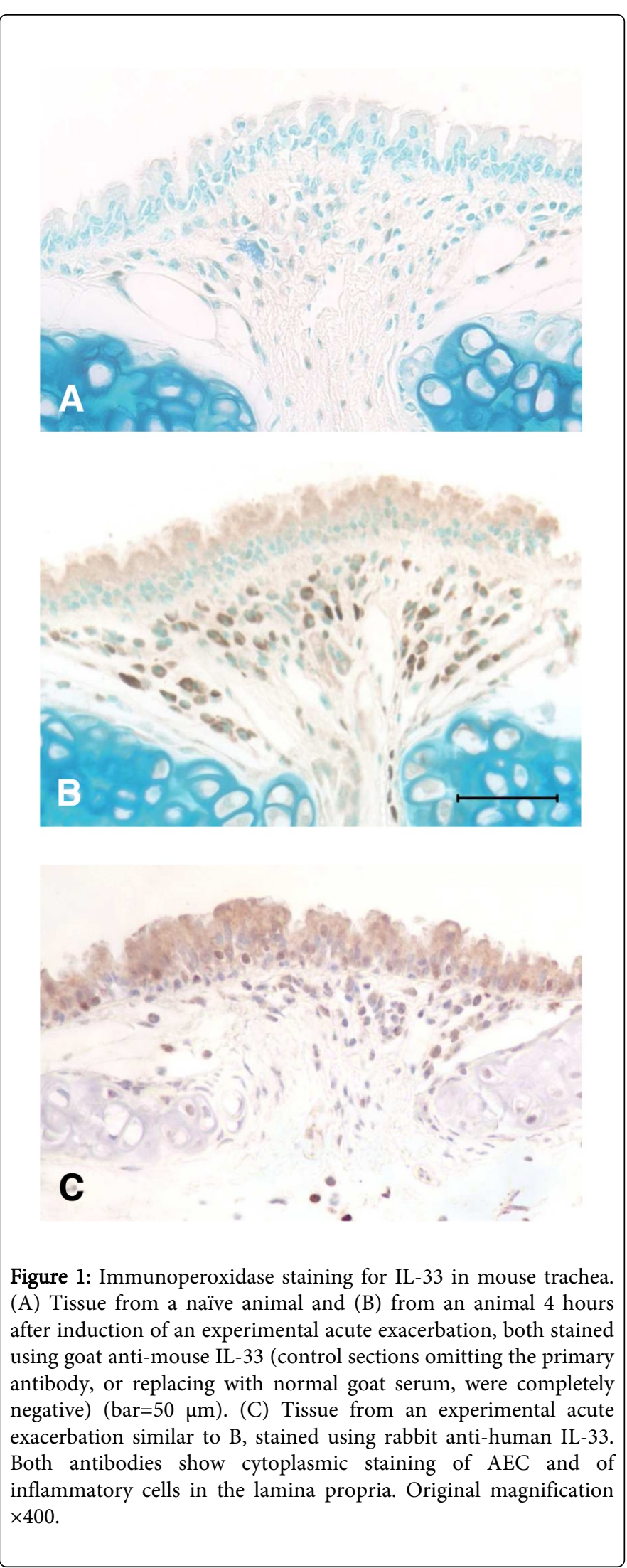

Double-label immunofluorescence staining was performed as previously described [14], using goat anti-mouse IL-33 and a detection antibody conjugated to Alexa Fluor 555 (Invitrogen) plus F(ab)2 goat anti-mouse immunoglobulins conjugated to fluorescein isothiocyanate (FITC) (Jackson Immunoresearch, West Grove, PA, USA).

\section{Results and Discussion}

Immunoperoxidase staining of sections of mouse trachea from the model of an acute exacerbation of chronic asthma ( $\mathrm{n}=8$ animals per group) demonstrated markedly stronger immunoreactivity for IL-33 in the cytoplasm of AEC (Figure 1A and 1B). Using semi-quantitative scoring of the intensity of immunoreactivity, we have previously shown that this represents a statistically significant increase in expression of the protein [4]. In parallel, there was also cytoplasmic immunostaining of inflammatory cells within the lamina propria of the airway wall (Figure 1B).

Because there was no evidence of nuclear immunoreactivity in mouse tissues using the goat antibody, we also performed immunohistochemistry using a cross-reactive rabbit antibody to human IL-33. This yielded a pattern of immunostaining in mice which was indistinguishable from that obtained with the goat antibody (Figure 1C).
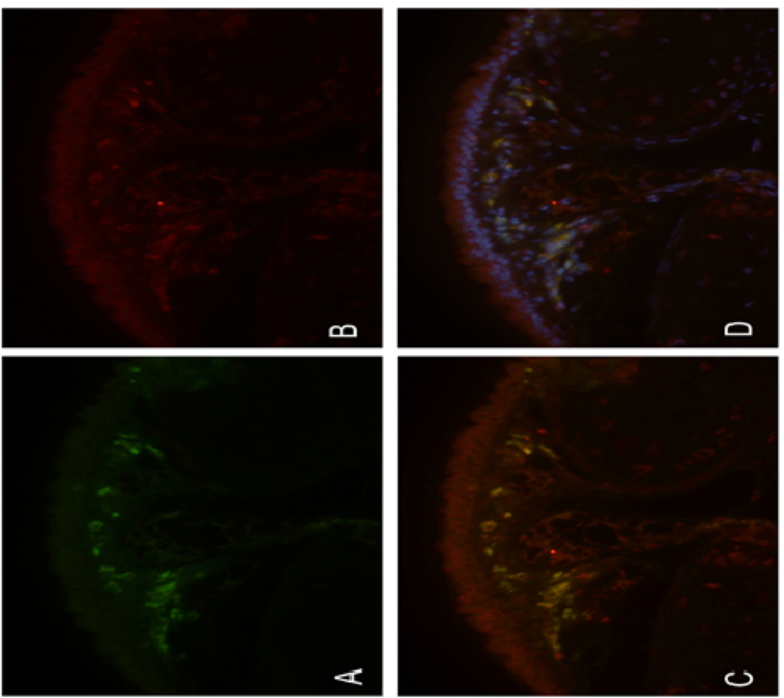

Figure 2: Double-label immunofluorescence staining for IL-33 and IgG. (A) Inflammatory cells in the lamina propria of the trachea demonstrating immunoreactivity for cytoplasmic $\operatorname{IgG}$, using an FITC-labeled antibody which fluoresces green. (B) Same field showing tracheal epithelium and inflammatory cells in the lamina propria demonstrating immunoreactivity for IL-33, using an Alexa Fluor 555-labeled antibody which fluoresces red. (C) Digitally merged image of A and B, demonstrating co-localisation of IL-33 in inflammatory cells in the lamina propria with cytoplasmic IgG, seen as yellow, confirming that these are plasma cells. Note non-colocalising staining for IL-33 in the tracheal epithelium. (D) Digitally merged image of $\mathrm{C}$ with a further image of the same field demonstrating staining of nuclei of epithelium and inflammatory cells, using DAPI which fluoresces blue. Original magnification $\times 400$. 


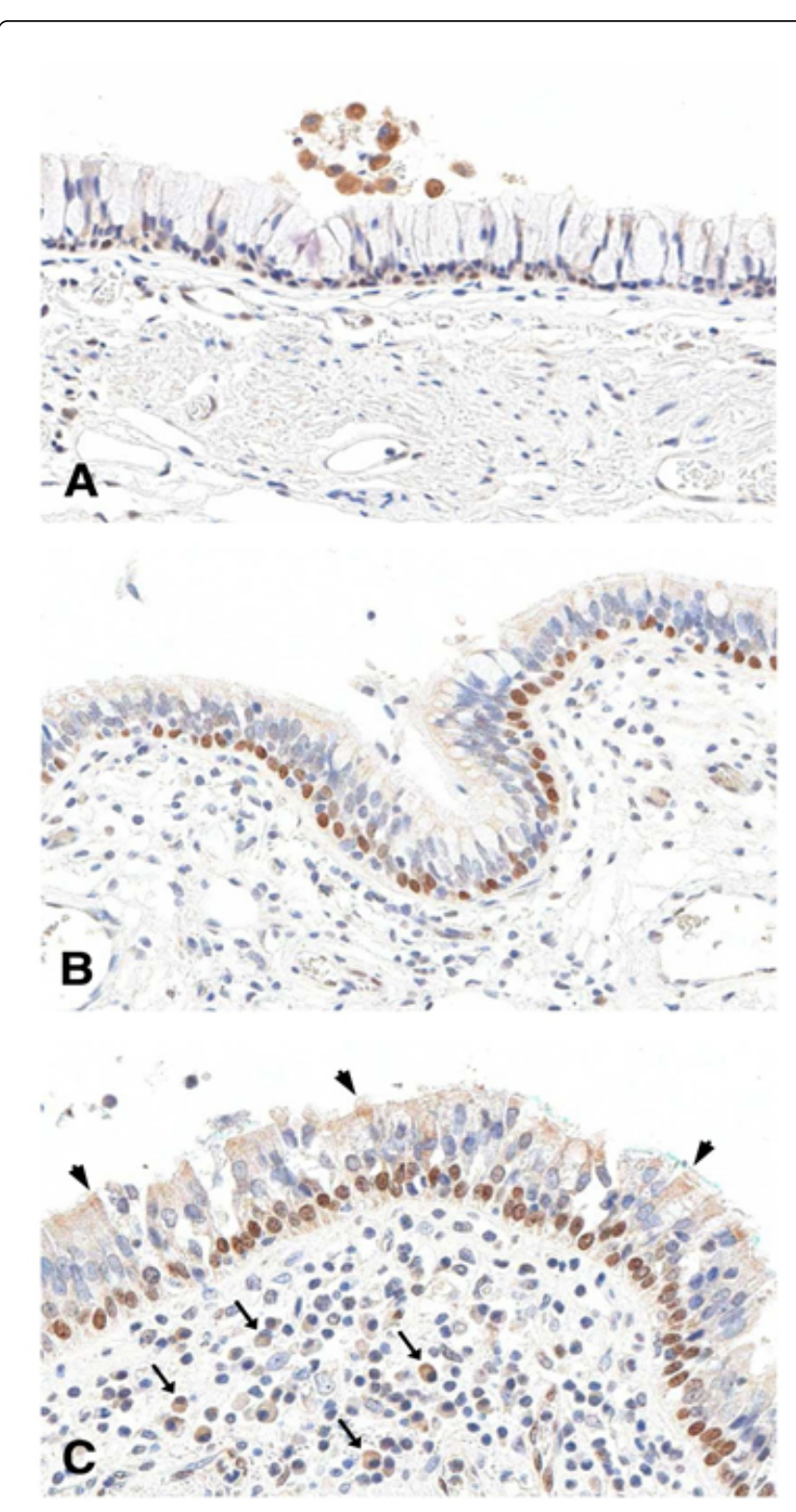

Figure 3: Immunoperoxidase staining for IL-33 in human airways. (A) Control tissue from a patient with mild chronic obstructive pulmonary disease, showing minimal epithelial staining (note cytoplasmic staining of macrophages). (B) Airway tissue from an asthmatic patient, showing strong nuclear staining of bronchiolar epithelium. (C) Airway tissue from a patient with ABPA, showing nuclear staining of bronchiolar epithelium together with apical cytoplasmic staining (arrowheads) as well as cytoplasmic staining of plasma cells in the lamina propria (arrows). Original magnification $\times 400$.

The inflammatory cells in the lamina propria were characterised as plasma cells based on their expression of cytoplasmic IgG. This was demonstrated using double-label immunofluorescence staining for IgG and IL-33 (Figure 2A-D). No staining for IL-33 was observed in the absence of the primary antibody, confirming that staining of plasma cells was not due to non-specific binding of detection antibodies to mouse immunoglobulins.

In control human airway tissue, there was minimal evidence of staining of epithelial cells (Figure 3A). In contrast, in human asthmatic airways $(n=5)$ there was strong nuclear immunoreactivity of epithelial cells, with little if any evidence of cytoplasmic staining (Figure 3B).

Because plasma cells are infrequent in the airway wall in human asthma, we further investigated the pattern of immunostaining for IL-33 in specimens of allergic bronchopulmonary aspergillosis (ABPA) $(n=4)$. In this setting of severe allergic inflammation, not only was there strong nuclear immunoreactivity of human AEC, but in addition cytoplasmic staining of these cells was apparent. Moreover, strong cytoplasmic staining of inflammatory cells in the lamina propria, with the distinctive morphology of plasma cells, was clearly evident (Figure 3C).

Collectively, these observations suggest that for IL-33, both the target species and the severity of the allergic inflammatory response influence the pattern of immunoreactivity observed in airway epithelial cells. Thus while there is no doubt that in humans, immunostaining for IL-33 in AEC is primarily observed in nuclei, it seems inappropriate to dismiss cytoplasmic immunoreactivity for this cytokine as simply an artefact. It is now clear that IL-33 may be actively transported into the cytoplasm in response to stress [15]. Our observation of cytoplasmic immunoreactivity in both mouse and human cells in the setting of severe allergic inflammation is consistent with these data. Moreover, our findings are supported by recent evidence of enhanced cytoplasmic immunoreactivity for IL-33 in the airway epithelium in smokers [16] as well as by similar findings in skin keratinocytes in another allergic disease, namely contact dermatitis [17].

The demonstration that plasma cells express high levels of IL-33 is novel. Plasma cells are usually not considered to be a significant source of inflammatory cytokines. However, our finding that plasma cells in pulmonary allergic disease exhibit cytoplasmic staining for IL-33 is consistent not only with observations in human inflammatory bowel disease [10] but also with other published evidence that these cells may be a major source of cytokines [18,19], including our previous report of eotaxin-1 expression by plasma cells [14]. IL-33 from plasma cells may have a role in driving allergic inflammation.

\section{References}

1. Liew FY, Pitman NI, McInnes IB (2010) Disease-associated functions of IL-33: the new kid in the IL-1 family. Nat Rev Immunol 10: 103-110.

2. Cayrol C, Girard JP (2014) IL-33: an alarmin cytokine with crucial roles in innate immunity, inflammation and allergy. Curr Opin Immunol 31C: 31-37.

3. Kurokawa M, Matsukura S, Kawaguchi M, Ieki K, Suzuki S, et al. (2011) Expression and effects of IL-33 and ST2 in allergic bronchial asthma: IL-33 induces eotaxin production in lung fibroblasts. Int Arch Allergy Immunol 155 Suppl 1: 12-20.

4. Bunting MM, Shadie AM, Flesher RP, Nikiforova V, Garthwaite L, et al. (2013) Interleukin-33 drives activation of alveolar macrophages and airway inflammation in a mouse model of acute exacerbation of chronic asthma. Biomed Res Int: 250938.

5. Kurowska-Stolarska M, Stolarski B, Kewin P, Murphy G, Corrigan CJ, et al. (2009) IL-33 amplifies the polarization of alternatively activated macrophages that contribute to airway inflammation. J Immunol 183: 6469-6477. 
Citation: Herbert C, Bunting MM, Lambie N, Thomas PS, Kumar RK (2015) Immunoreactivity for Interleukin-33 in Allergic Airway Inflammation. J

6. Préfontaine D, Nadigel J, Chouiali F, Audusseau S, Semlali A, et al. (2010) Increased IL-33 expression by epithelial cells in bronchial asthma. J Allergy Clin Immunol 125: 752-754.

7. Bessa J, Meyer CA, de Vera Mudry MC, Schlicht S, Smith SH, et al. (2014) Altered subcellular localization of IL-33 leads to non-resolving lethal inflammation. J Autoimmun 55: 33-41.

8. Kurowska-Stolarska M, Kewin P, Murphy G, Russo RC, Stolarski B, et al (2008) IL-33 induces antigen-specific IL-5+ T cells and promotes allergic-induced airway inflammation independent of IL-4. J Immunol 181: 4780-4790.

9. Kim HY, Chang YJ, Subramanian S, Lee HH, Albacker LA, et al. (2012) Innate lymphoid cells responding to IL-33 mediate airway hyperreactivity independently of adaptive immunity. J Allergy Clin Immunol 129: 216-227.

10. Pastorelli L, Garg RR, Hoang SB, Spina L, Mattioli B, et al. (2010) Epithelial-derived IL-33 and its receptor ST2 are dysregulated in ulcerative colitis and in experimental Th1/Th2 driven enteritis. Proc Natl Acad Sci U S A 107: 8017-8022.

11. Pichery M, Mirey E, Mercier P, Lefrancais E, Dujardin A, et al. (2012) Endogenous IL-33 is highly expressed in mouse epithelial barrier tissues, lymphoid organs, brain, embryos, and inflamed tissues: in situ analysis using a novel Il-33-LacZ gene trap reporter strain. J Immunol 188: 3488-3495.

12. Temelkovski J, Hogan SP, Shepherd DP, Foster PS, Kumar RK (1998) An improved murine model of asthma: selective airway inflammation, epithelial lesions and increased methacholine responsiveness following chronic exposure to aerosolised allergen. Thorax 53: 849-856.

13. Siegle JS, Hansbro N, Herbert C, Yang M, Foster PS, et al. (2006) Airway hyperreactivity in exacerbation of chronic asthma is independent of eosinophilic inflammation. Am J Respir Cell Mol Biol 35: 565-570.

14. Kumar RK, Thomas PS, Seetoo DQ, Herbert C, McKenzie AN, et al. (2002) Eotaxin expression by epithelial cells and plasma cells in chronic asthma. Lab Invest 82: 495-504.

15. Kakkar R, Hei H, Dobner S, Lee RT (2012) Interleukin 33 as a mechanically responsive cytokine secreted by living cells. J Biol Chem 287: 6941-6948.

16. Pace E, Di Sano C, Sciarrino S, Scafidi V, Ferraro M, et al. (2014) Cigarette smoke alters IL-33 expression and release in airway epithelial cells. Biochim Biophys Acta 1842: 1630-1637.

17. Mattii M, Ayala F, Balato N, Filotico R, Lembo S, et al. (2013) The balance between pro- and anti-inflammatory cytokines is crucial in human allergic contact dermatitis pathogenesis: the role of IL-1 family members. Exp Dermatol 22: 813-819.

18. Di Girolamo N, Visvanathan K, Lloyd A, Wakefield D (1997) Expression of TNF-alpha by human plasma cells in chronic inflammation. J Leukoc Biol 61: 667-678.

19. Zhu J, Qiu Y, Valobra M, Qiu S, Majumdar S, et al. (2007) Plasma cells and IL-4 in chronic bronchitis and chronic obstructive pulmonary disease. 1, Am J Respir Crit Care Med 175: 1125-1133. 